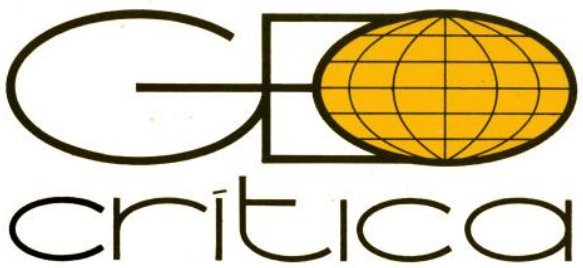

Vol. XXIV. Núm. 243

I de junio de 2020

DOI: https://doi.org/I0.1344/ara2020.243.31627

\title{
EMPOBRECIMIENTO DE LOS HOGARES Y CAMBIOS EN EL ABASTECIMIENTO DE ALIMENTOS POR LA COVID-I 9 EN LIMA, PERÚ
}

\author{
Tania Herrera Romero \\ Universidad Nacional Mayor de San Marcos - Perú \\ therrerar@unmsm.edu.pe \\ Aurélien Reys \\ PhD Geografía del Desarrollo, Université Paris Diderot - Francia \\ aurelienreys@gmail.com
}

\section{Empobrecimiento de los hogares y cambios en el abastecimiento de alimentos por la COVID-I 9 en Lima, Perú (Resumen)}

A partir de datos originales producidos gracias a un cuestionario virtual, se analizan las consecuencias de dos medidas tomadas por las autoridades peruanas en el contexto de la crisis sanitaria de COVID-19. Primero, cuestionamos el impacto económico de la inmovilización social (cuarentena) en los hogares de Lima Metropolitana. Nuestro enfoque, comparativo por clase socioeconómica, revela que los hogares más pobres son los más vulnerables debido a que perdieron sus trabajos en mayor número, lo que resultó en una disminución muy significativa de sus ingresos. Luego, cuestionamos la medida "pico y placa por género" a la luz de los cambios que identificamos en los hábitos de abastecimiento de alimentos, antes y después de la cuarentena. Con la cuarentena, los hogares redujeron el número de veces en que hacían compras y, pese a la disminución de brechas de género, estas tareas aún reposan largamente en las mujeres, independientemente de su clase socioeconómica.

Palabras clave: COVID-19, cuarentena, vulnerabilidad socioeconómica, pobreza, Lima.

Household impoverishment and changes in food supply due to COVID-19 in Lima, Peru (Abstract)

Using original data produced through a virtual questionnaire, we analyze the consequences of two measures taken by the Peruvian authorities in the context of the COVID-19 health crisis. In the first part we question the economic impact of social immobilization (quarantine) on households in Metropolitan Lima. Our 
comparative approach, by socioeconomic class, reveals that the poorest households are the most vulnerable as they lost their jobs in greater numbers, resulting in a very significant decrease in their income. In the second part, we discuss the "pico y placa por género" measure in light of the changes we identified in food supply habits before and after quarantine. With quarantine, households reduced the number of times they made purchases and, despite the narrowing of gender gaps, these tasks remain largely in the hands of women, regardless of socioeconomic class.

Keywords: COVID-19, quarantine, socioeconomic vulnerability, poverty, Lima

El viernes 06 de marzo de 2020 se conoció el primer caso de COVID-19 en el Perú. Cinco días después, el Ministerio de Salud emitió la Declaratoria de Emergencia Sanitaria por noventa días a raíz de que la Organización Mundial de la Salud (OMS) calificara de pandemia al COVID-19. Desde ese día, se desplegó una serie de medidas de prevención y control para evitar la propagación del virus: se suspendieron actividades educativas y, en relación al flujo migratorio, se estableció que los viajeros provenientes de Italia, España, Francia y China debían pasar catorce días en aislamiento domiciliario ${ }^{1}$. El Gobierno instó a tomar medidas para evitar la propagación del virus en los medios de transporte, en centros laborales, y sugirió evitar la concentración de personas en espacios públicos y privados.

Las medidas no se intensificaron hasta la noche del 15 de marzo, cuando se declaró el "Estado de Emergencia Nacional" por quince días y se dispuso "el aislamiento social obligatorio (cuarentena)" ". Con esta medida, se suspendió el ejercicio de derechos constitucionales, se limitó el ejercicio del derecho a la libertad de tránsito de las personas, quedó restringido el acceso a locales y establecimientos, "a excepción de los establecimientos comerciales minoristas de alimentación, bebidas, productos y bienes de primera necesidad, establecimientos farmacéuticos, médicos, ópticas y productos ortopédicos, productos higiénicos, grifos y establecimientos de venta de combustible"3. Además del cierre de fronteras y la suspensión del transporte internacional e interprovincial de pasajeros, se redujo a la mitad la oferta del transporte urbano en el territorio nacional. Así, muchos centros de producción y de servicios dejaron de funcionar.

El punto de partida de este trabajo, iniciado los primeros días de abril 2020, fue el inédito contexto de urgencia que llevó a la promulgación -sobre la marcha- de medidas sanitarias que tenían por objetivo evitar el aumento de contagios por la pandemia del COVID-19. En ese momento, nos interpeló la prorrogación de la cuarentena, medida de carácter sanitario que no parecía considerar la vulnerabilidad de los hogares más pobres. Para estos hogares, el trabajo independiente (formal e informal) aporta ingresos diarios que permiten su subsistencia, con muy poca o ninguna

\footnotetext{
1 Decreto Supremo $\mathrm{N}^{\circ}$ 008-2020-SA, p. 7 <https://busquedas.elperuano.pe/normaslegales/decreto-supremo-quedeclara-en-emergencia-sanitaria-a-nivel-decreto-supremo-n-008-2020-sa-1863981-2/>.

${ }^{2}$ Decreto Supremo No 044-2020-PCM, p. 11 <https://www.gob.pe/institucion/pcm/normas-legales/460472-044-2020$\mathrm{pcm}>$.

${ }^{3}$ La inmovilización social obligatoria implica que nadie puede salir de su casa entre las 18:00 y las 05:00 horas, salvo para los departamentos Tumbes, Piura, Lambayeque, La Libertad y Loreto donde la restricción es entre las 16:00 y las 04:00 horas (Decreto Supremo No 064-2020-PCM, p.10). La compra de alimentos y medicinas, así como la realización de trámites financieros son las principales razones por las que las personas pueden salir de sus hogares; deben hacerlo portando una mascarilla y solo está permitido que lo haga un miembro del hogar entre los días lunes y sábado (op.cit.) <https://www.gob.pe/institucion/pcm/normas-legales/473387-064-2020-pcm>.
} 
Empobrecimiento de los hogares y cambios en el abastecimiento de alimentos por la COVID-I9 en Lima...

protección por parte del Estado ${ }^{4}$. Sospechamos que, pese a la prohibición, algunas de estas actividades podían continuar de alguna manera ${ }^{5}$, lo que podría acelerar la circulación incontrolada y la expansión del virus en las zonas geográficas más pobres de la ciudad y del país. También nos cuestionó la medida "pico y placa por género"6, que buscaba restringir la movilización social semanal según el género de las personas y, desde el día en que se dio a conocer, suscitó vivo rechazo en las redes sociales ${ }^{7}$ pues parecía ignorar el histórico peso de las mujeres peruanas en tareas de cuidado en el hogar.

La decisión del Gobierno del Perú de introducir medidas estrictas de distanciamiento social iba a tono con políticas similares, aplicadas unos días antes por países europeos gravemente afectados por la epidemia (Italia, Francia, España). Las autoridades peruanas temían reaccionar demasiado tarde y de manera imprecisa para detener la contaminación de la población. Las medidas sanitarias surgieron luego de que se publicaran trabajos científicos sobre el Coronavirus, los que dieron a conocer las características epidemiológicas del virus y su dinámica de transmisión ${ }^{8}$. En estos trabajos se propusieron tratamientos ${ }^{9}$ que resultaron eficaces para frenar la letalidad del virus, lo que sugería que, detrás de la crisis sanitaria mundial desatada por el COVID-19, había algo más.

La aparente serenidad de los poderes públicos se erosionó muy rápidamente ante el crecimiento exponencial de los muertos y la publicación de informes de investigaciones realizadas, en particular los producidos por el epidemiólogo Neil Ferguson y sus colaboradores. Los informes demostraron, mediante modelos matemáticos, que, en ausencia de medidas de distanciamiento social, el número de muertes podía llegar a varios cientos de miles en países como el Reino Unido y a millones en los Estados Unidos ${ }^{10}$, afectando en primer lugar a las poblaciones más vulnerables: adultos mayores ya internados por problemas de salud, personas sin techo, trabajadores migrantes, entre otros ${ }^{11}$. La vulnerabilidad se revelaba mayor para los países más pobres que, pese a tener principalmente población joven -aparentemente menos susceptible al COVID-19-, mantienen serias deficiencias en cuanto a la cobertura de salud, de vivienda y de educación ${ }^{12}$. Varios autores apuntaron que la

\footnotetext{
${ }^{4}$ Al 27 de abril, la cuarentena ya se ha prorrogado en tres ocasiones y se ha extendido hasta el 10 de mayo de 2020.

${ }^{5}$ Como ha sido la experiencia en otros países. Ver <https://theconversation.com/sauver-leconomie-informelle-faceau-covid-19-en-afrique-de-louest-137822>.

${ }^{6}$ La expresión se deriva de la restricción a la circulación en auto privado según la matriculación (la placa). La norma, popularizada como "pico y placa por género", fue anunciada por el Presidente de la República Martín Vizcarra y emitida el jueves 02 de abril, estableciendo que "Los días lunes, miércoles y viernes únicamente podrán transitar personas del sexo masculino y los martes, jueves y sábados las personas del sexo femenino. Asimismo, el día domingo, la inmovilización social obligatoria es para todos los ciudadanos en el territorio nacional durante todo el día" (Decreto Supremo No 057-2020-PCM, p. 2). Tras recibir fuertes críticas, el 10 de abril la medida quedó sin efecto, pero se mantuvo la interdicción de salir el día domingo (Decreto Supremo No 064-2020-PCM, p. 10) <https://www.gob.pe/institucion/pcm/normas-legales/466151-057-2020-pcm> $<$ https://www.gob.pe/institucion/pcm/normas-legales/473387-064-2020-pcm>.

${ }^{7}$ La congresista Rocío Silva Santisteban criticó la medida señalando la predominancia de mujeres jefas de hogar y su rol como cuidadoras <https://twitter.com/pavese/status/1245773429921456130>.

$8 \mathrm{Li}$ et al., 2020 <https://www.nejm.org/doi/full/10.1056/NEJMoa2001316>; Zhou et al., 2020 <https://www.thelancet.com/pb-assets/Lancet/pdfs/S014067362305663.pdf> ; $\quad$ Liu $\quad$ et al., 2020 <https://academic.oup.com/jtm/article/27/2/taaa021/5735319>.

${ }^{9}$ Gao, Tian \& Yang, 2020.

10 Adam, 2020 <https://www.nature.com/articles/d41586-020-01003-6> ; Ferguson et al., 2020 <https://spiral.imperial.ac.uk:8443/bitstream/10044/1/77482/15/2020-03-16-COVID19-Report-9-Spanish.pdf>.

${ }^{11}$ Haley et al, $2020<$ https://www.foodsystemsjournal.org/index.php/fsj/article/view/810>.

12 Buj, $2020<$ https://www.raco.cat/index.php/Aracne/article/view/367759>.
} 
política de la cuarentena respondía a la contención colectiva de un debilitado sistema de salud pública universal, carcomido en las últimas décadas por las políticas que lo privatizaron en alianza con la industria farmacéutica ${ }^{13}$.

La decisión de las autoridades peruanas de instaurar el confinamiento en todo el país se inscribe en el contexto mundial de miedo, acentuado por el hecho de que los países menos solventes y más vulnerables en el plano económico ${ }^{14}$, como Perú, presentan características que pueden agravar los efectos de la crisis sanitaria, especialmente para sus poblaciones más pobres ${ }^{15}$. Por ello, las medidas aplicadas se pusieron en práctica rápidamente y, a nuestro juicio, sin tener realmente en cuenta las consecuencias directas e indirectas que conllevarían. Frente a esto, nos pareció necesario indagar cómo llevaban estas medidas los hogares de Lima Metropolitana, y nos propusimos analizar los cambios en los hábitos de compra de alimentos a través de un cuestionario virtual ${ }^{16}$. Nuestra aproximación fue a través de las consecuencias económicas directas, presentes y futuras, de la inmovilización social y de la restricción de movilidad por género, según las diferentes clases sociales. En este trabajo buscamos comprender cómo afectan estas medidas a la economía de los hogares y sus hábitos de abastecimiento de alimentos y, en qué medida, estos hábitos varían según las clases sociales y los espacios geográficos de la ciudad.

A manera de hipótesis consideramos, por una parte, que las medidas son sufridas de manera muy brutal por los hogares más desfavorecidos y, por otra parte, que la diferenciación según género no permite reducir la frecuencia de los desplazamientos con fines alimentarios; por el contrario, los desplazamientos restringidos según género tienden a favorecer el aumento de las densidades (concentración de personas) en los puntos de compra de alimentos.

Durante la escritura de este artículo se habían publicado muy pocos trabajos relacionados al COVID-19 en los campos de la geografía y las ciencias sociales. Entre ellos, se encuentra la revista brasileña de geografía económica Espaço e Economia, que rápidamente dedicó un número doble a la crisis de COVID-19 ${ }^{17}$. Este número estuvo compuesto, principalmente, por artículos de tipo descriptivo que hacen un balance de la situación en los estados federales brasileños, en los países de América Latina y del sur de Europa, e incluyen algunos análisis muy generales y críticos de la globalización, la hipermovilidad y, de manera más general, del capitalismo. Desde el punto de vista económico, los posibles impactos se evalúan principalmente a escala macroeconómica, destacando en particular el problema que podría causar la deuda ${ }^{18}$. Desde el punto de vista geográfico, la dinámica de la difusión del virus en el espacio se refleja en los factores que han favorecido su expansión, como las densidades de población o la fuerte conectividad de unos territorios con otros a través del transporte. Respecto a la universalización de los elementos patógenos, Antonio Buj

${ }_{13}$ Davis, 2005; 2020 <https://newleftreview.org/issues/II122/articles/mike-davis-in-a-plague-year>; Harvey 2020 <https://jacobinmag.com/2020/03/david-harvey-coronavirus-political-economy-disruptions>.

${ }^{14}$ Gilbert et al, 2020 < https://www.medrxiv.org/content/10.1101/2020.02.05.20020792v1>.

${ }^{15}$ Davis, 2005.

${ }^{16}$ Para el Instituto Nacional de Estadística e Informática, el hogar “(...) es la agrupación primaria que permite atender las necesidades de supervivencia de sus miembros y, a su vez, es el elemento primario de la organización social. En general, los hogares adoptan diferentes tipos de arreglos, que tienen como núcleo fundamental a la pareja con o sin hijos, al que se agregan otras personas con las que pueden o no tener relaciones de parentesco" (INEI, 2018: 355). Los hogares pueden estar conformados por una sola persona.

17 Espaço e Economia, 2020a <https://journals.openedition.org/espacoeconomia/10071〉, 2020b $<$ https://journals.openedition.org/espacoeconomia/11397>.

${ }^{18}$ Op.cit. en nota 13. 
Empobrecimiento de los hogares y cambios en el abastecimiento de alimentos por la COVID-I9 en Lima...

incide en la recurrencia de las epidemias y plagas en diferentes partes del mundo, hecho que demuestra que no eran eventos desconocidos para la humanidad y, sin embargo, se abandonó la salud pública internacional al tiempo que se demolían los Estados de bienestar desde finales de $1970^{19}$.

El trabajo que hicimos se inscribe en esa primera ola de reflexiones sobre el COVID-19 en ciudades latinoamericanas. Los primeros resultados fueron publicados rápidamente en una página web de divulgación nacional, pues vimos necesario difundir información sobre la dramática situación económica que afrontaban los hogares más pobres de Lima $^{20}$. Para el presente artículo ampliamos y profundizamos el análisis sobre la base de los resultados iniciales, con mayor énfasis en la dimensión geográfica de las consecuencias económicas de la cuarentena. Consideramos que los datos recogidos y los resultados de los análisis que exponemos en este documento son cruciales para las respuestas que deben dar los poderes públicos en un momento en el que, según la CEPAL, América Latina se prepara para afrontar la mayor crisis económica de su historia ${ }^{21}$.

\section{Metodología}

Este trabajo se basa, en primer lugar, en los datos originales producidos gracias a un cuestionario hecho en Google Formulario con un total de 33 preguntas, que compartimos entre las 13:00 horas del martes 07 y las 08:00 horas del miércoles 09 de abril. El cuestionario se compartió, por correo electrónico, a estudiantes y docentes de la especialidad de Geografía de la Universidad Nacional Mayor de San Marcos. También lo difundimos vía Facebook en páginas de municipalidades, de asociaciones civiles, de organismos no gubernamentales, de equipos de futbol, de partidos políticos, entre otros. Cuando no fue posible compartir públicamente el cuestionario, se compartió como mensaje privado, sin obtener respuesta de manera sistemática. En todos los casos, se solicitó a los encuestados que compartieran el cuestionario entre sus contactos. En total, obtuvimos 356 respuestas, de las cuales eliminamos 2 debido a que faltaban datos fundamentales para nuestra investigación, lo que dejó un total de 354 respuestas consideradas al final.

Nuestro enfoque se inscribe, en primer lugar, en una lógica comparativa entre las diferentes clases socioeconómicas. Para la clasificación de la categoría socioeconómica según ingresos, consideramos como punto de partida la propuesta del Instituto Nacional de Estadística e Informática $(2016)^{22}$ que readaptamos. A partir de estos estratos y según los ingresos totales de los hogares encuestados, obtuvimos 33 respuestas de hogares de clase baja (ingresos inferiores a S/.898.99), 90 respuestas de hogares de clase media (ingresos entre S/. 899 y S/.2192.19), 96 respuestas de hogares de clase alta (ingresos entre S/. 2192.20 y S/.4384.39) y 126 respuestas de hogares de clase más alta (ingresos de S/. 4384.40 a más) (ver Figura 1). Las comparaciones se

\footnotetext{
${ }^{19}$ Buj, $2020<$ https://www.raco.cat/index.php/Aracne/article/view/367759>.

${ }^{20}$ Publicado el 14 de abril en la página web de Ojo Zurdo, Revista de Política y Cultura. Disponible en $<$ https://revistaojozurdo.pe/2020/04/14/inmovilizacion/>.

21 CEPAL, $2020<$ https://www.cepal.org/es/comunicados/pandemia-COVID-19-llevara-la-mayor-contraccion-laactividad-economica-la-historia-la>.

${ }^{22}$ El INEI (2016) establece en estrato bajo los hogares cuyos ingresos per cápita no alcanzan los S/.575.69, medio bajo cuando los ingresos están entre S/.575.70 y S/.898.99, medio cuando están entre S/.899 y S/.1330.09, medio alto cuando están entre S/.1330.10 y S/.2192.19, y alto cuando superan los S/.2192.20.
} 
realizan principalmente mediante estadísticas descriptivas y los resultados se representan con ayuda de soportes gráficos.

\section{Descripción del espacio de estudio y de la muestra}

Nuestra área de estudio es la conurbación de la Provincia de Lima y de la Provincia Constitucional de El Callao, espacio que denominaremos en adelante Lima Metropolitana. La ciudad se extiende sobre tres valles costeros, pertenecientes a los ríos Chillón, Rímac y Lurín, y comprende cincuenta distritos, donde habita un total de 10.209.275 personas $^{23}$. La urbanización de este espacio cambió radicalmente a partir de 1940, cuando el parque de viviendas era insuficiente para albergar a la población existente y para recibir a las centenas de inmigrantes que llegaban continuamente ${ }^{24}$. Ante la inexistente oferta de vivienda pública o privada, la autoconstrucción y la autourbanización constituyeron la salida por excelencia para los habitantes de la ciudad ${ }^{25}$. Las barriadas se establecieron entre las áreas centrales y las estribaciones andinas. En los últimos veinte años, vemos que ante la falta de suelo en zonas planas y de oferta de vivienda asequible, los más pobres ocupan los cerros que circundan a los barrios ya consolidados, pese a su difícil accesibilidad y domesticación $^{26}$. Quienes sí cuentan con los recursos suficientes se instalan en las áreas centrales de la ciudad, o próximos al litoral, configurando así un espacio intraurbano altamente desigual.

Podemos ver que la población de nuestro cuestionario ofrece una buena impresión de esta geografía de clases sociales en la metrópoli limeña (ver Figura 1). En nuestro trabajo, están representados los hogares más adinerados que viven en zonas calificadas por la Cámara Peruana de la Construcción (CAPECO) como Lima Top, Lima Moderna y Lima Centro. También hay representación de aquellos hogares hacia las periferias de la ciudad, con ingresos más modestos, que viven en lo que CAPECO denomina Lima Norte, Este y Sur.

\footnotetext{
${ }^{23}$ INEI, 2017 <https://censos2017.inei.gob.pe/redatam/>.

${ }^{24}$ Driant, 1991; Deler, 1974; Barreda y Ramírez Corzo, 2004.

${ }^{25}$ Driant y Riofrío, 1987.

${ }^{26}$ Ramírez Corzo y Riofrío, 2006; Barreda y Ramírez Corzo, 2004.
} 
Empobrecimiento de los hogares y cambios en el abastecimiento de alimentos por la COVID-19 en Lima...

Figura 1. Distribución de los encuestados según zonas de lima y clases sociales

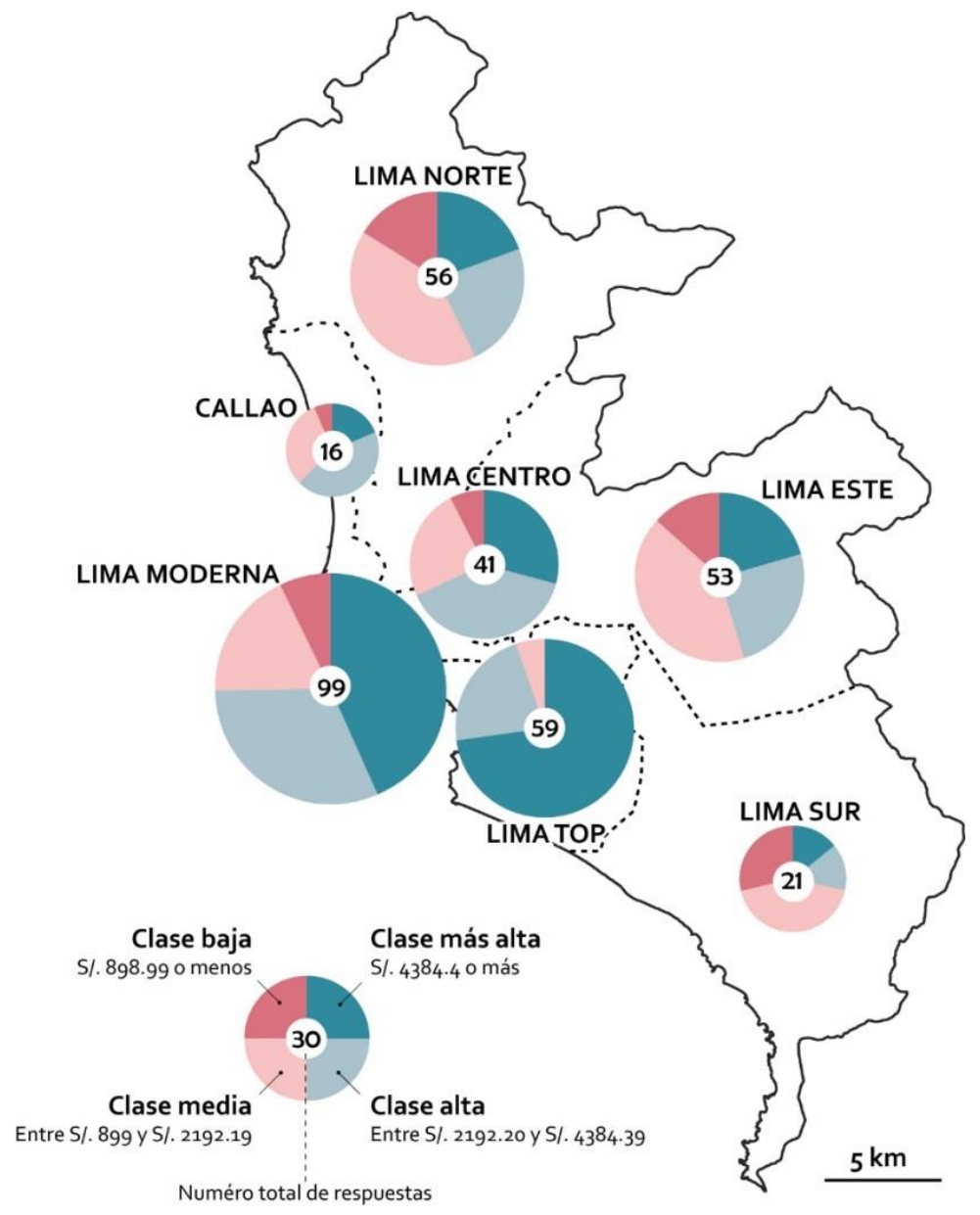

Fuente: CAPECO (RPP, 2015) y encuesta propia.

Nota: En nueve de las 354 respuestas los encuestados no precisaron su distrito de residencia, por lo que este gráfico se hizo sobre la base de 345 respuestas.

Elaboración: autores, abril 2020.

De esta manera, nuestro enfoque por clases socioeconómicas es también un enfoque por el espacio, en tanto que la desigualdad económica se expresa en la diferenciación espacial de los barrios y los distritos. Sin embargo, en nuestra investigación hay más encuestados pertenecientes a clases altas y medias. Buscamos compensar esta situación durante el procesamiento de los datos al no considerar un total desclasado y, antes bien, incluir sistemáticamente el total de respuestas por cada clase social. De igual modo, el mayor número de encuestados de algunas clases socioeconómicas no parece ser un mayor problema debido a que, en términos de características demográficas, encontramos pocas diferencias estadísticamente significativas ${ }^{27}$ entre las clases (ver Cuadro 1).

${ }^{27}$ A una tasa del 5\% o menos, utilizando el Test-T; solo son significativas las diferencias en el número de personas por hogar entre las clases Baja y Media, y el porcentaje de personas mayores entre las clases Baja y Alta. 
Cuadro 1. Perfil de los hogares según clases sociales

\begin{tabular}{|l|r|r|r|r|}
\hline Clase & \multicolumn{1}{|c|}{$\begin{array}{c}\text { Número de } \\
\text { personas en el } \\
\text { hogar }\end{array}$} & $\begin{array}{c}\text { Menos de 18 } \\
\text { años (\%) }\end{array}$ & $\begin{array}{c}\text { Más de 65 } \\
\text { años (\%) }\end{array}$ & \multicolumn{1}{c|}{$\begin{array}{c}\text { Mujeres } \\
(\%)\end{array}$} \\
\hline Más alta & 3.8 & 14.8 & 15.2 & 59.9 \\
\hline Alta & 4.1 & 16.8 & 17.0 & 62.6 \\
\hline Media & 4.8 & 15.3 & 12.7 & 60.5 \\
\hline Baja & $3.9 \mathrm{~m}$ & 20.6 & $9.0 \mathrm{a}$ & 57.6 \\
\hline
\end{tabular}

Fuente: encuesta propia.

Nota: las respuestas vacías fueron consideradas ausentes y no inválidas. Sin embargo, podemos pensar que algunos encuestados quisieron decir "cero" al dejar los espacios sin responder. Así, aunque de manera relativamente marginal, los porcentajes que se observan en la tabla pueden estar sobre-estimados.

Elaboración: autores, abril 2020.

Por lo tanto, aunque esto tendrá poca influencia en los resultados presentados, pueden observarse algunas leves variaciones. Así, en relación al número de personas por hogar, los hogares que pertenecen a clase media cuentan con la mayoría de individuos (4.8), seguidos por la clase alta (4.1), más alta (3.8) y baja (3.7). Los hogares de clase baja cuentan ligeramente con más niños y adolescentes: uno de cada cinco miembros tiene menos de 18 años. Por su parte, los hogares de clase alta y más alta cuentan con más personas mayores de 65 años: uno de cada seis miembros tiene más de 65 años. No se observa mayor diferencia respecto a la proporción de mujeres en el hogar según clase social: seis de cada diez miembros es mujer.

\section{Desigual distribución de la vulnerabilidad en los hogares de Lima}

Aunque no se trató de un plebiscito, la decisión de poner en cuarentena al país y confinar a la población parece ser, en general, objeto de consenso en todos los países del mundo, incluido el Perú. No obstante, el éxito de esas medidas depende de la capacidad de los países en desarrollo para aplicar rigurosamente todas las recomendaciones necesarias durante una crisis sanitaria de ese tipo, titánica tarea debido a la falta de medios e infraestructuras ${ }^{28}$. Por ello, la crisis sanitaria y sus consecuencias económicas resultan ser desiguales y afectan aún más a las poblaciones más pobres $^{29}$. En este contexto, las políticas monetarias de transferencia de ingresos buscan mitigar los efectos del desastre para las personas más vulnerables ${ }^{30}$.

Pese a la ambigüedad de su significado y al poco acuerdo en su definición, el concepto de vulnerabilidad se utiliza mucho desde 1980 en los estudios ambientales, especialmente en riesgos naturales, pero también en estudios socioeconómicos ${ }^{31}$. La vulnerabilidad ha sido definida como el grado en que un sistema social es afectado por un evento peligroso ${ }^{32} \mathrm{y}$, de manera general, se

\footnotetext{
${ }^{28}$ Davis, 2005; 2020 <https://newleftreview.org/issues/II122/articles/mike-davis-in-a-plague-year>.

29 Romero y Landmann Szwarcwald, $2000<$ https://www.scielo.br/scielo.php?script=sci_arttext\&pid=S0102311X2000000300028>; De Janvry y Sadoulet, 2005 <https://doi.org/10.1111/j.1475-4991.2000.tb00843.x>.

${ }^{30}$ Alencar et al., $2020<\mathrm{http}: / /$ journals.openedition.org/espacoeconomia/13734>.

${ }^{31}$ Méndez y Prada-Trigo, 2014 <http://www.ub.edu/geocrit/sn/sn-474.htm>; Ran et al, 2020.

32 Timmerman, 1981.
} 
Empobrecimiento de los hogares y cambios en el abastecimiento de alimentos por la COVID-I9 en Lima...

refiere a personas, grupos o territorios altamente expuestos a verse afectados, debido a una gran exposición a riesgos, su escasa capacidad de respuesta y adaptación ${ }^{33}$.

La vulnerabilidad es una construcción social en tanto que resulta de ideas y políticas que pueden evitar y reducir la sobre-exposición de las personas a sufrir daños. Asimismo, estas ideas y políticas pueden dejar sin protección social al conjunto de la sociedad y abandonar la satisfacción de las necesidades fundamentales en manos del mercado ${ }^{34}$. De este modo, conocer cómo ha sido la evolución de la vulnerabilidad, su construcción social en el tiempo, permitiría formular diversos escenarios de respuesta y adaptación a futuro ${ }^{35}$.

Tanto el tiempo como el espacio son fundamentales para entender la vulnerabilidad. Se habla de territorios y poblaciones vulnerables para señalar a aquellos que no siempre tienen seguridad social $\mathrm{y}$, particularmente, carecen de ingresos constantes que permitan satisfacer sus necesidades básicas ${ }^{36}$. En este sentido, la variación de la vulnerabilidad es indesligable de su contexto cultural y geográfico, fundamentales para las respuestas de la población y su posibilidad de adaptación ${ }^{37}$. Si la vulnerabilidad se distribuye desigualmente en el espacio, la recuperación post-crisis también tendrá un correlato espacialmente desigual, causado por los patrones heredados ${ }^{38}$. Esto se aplica a diferentes niveles, tanto en el ámbito nacional (debido a las desigualdades entre regiones) como en el intraurbano.

En relación a la variación intraurbana de la vulnerabilidad, observamos que en Lima Metropolitana la cuarentena tiene importantes consecuencias en las actividades profesionales y en los ingresos de los hogares, y vemos que las consecuencias difieren significativamente según la clase social, pues afecta mucho más gravemente a los hogares más pobres (ver Figura 2).

\footnotetext{
${ }^{33}$ Méndez y Prada-Trigo, op.cit. nota 26.

${ }^{34}$ Méndez y Prada-Trigo, op.cit. nota 26.

${ }^{35}$ Ran et al, 2020.

${ }^{36}$ Fortes, de Oliveira y de Sousa $2020<$ http://journals.openedition.org/espacoeconomia/13591>; Soares de Farias, $2020<$ http://journals.openedition.org/espacoeconomia/11357>.

${ }^{37}$ Ran et al, op.cit. nota 30.

${ }^{38}$ Prada-Trigo, 2018: 19 <https://www.raco.cat/index.php/ScriptaNova/article/view/337246>.
} 
Figura 2. Situación económica de los hogares durante la cuarentena

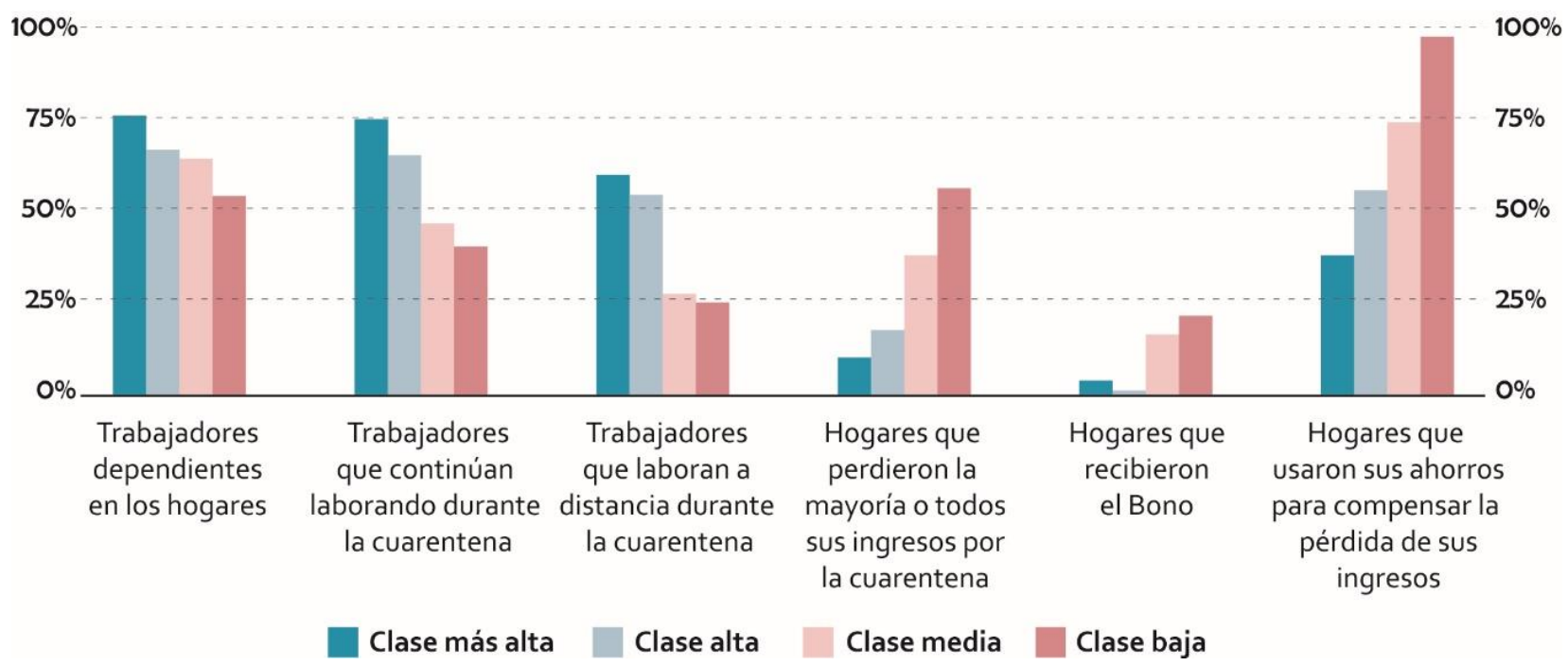

Fuente: Encuesta propia. Elaboración: autores, abril 2020.

Las pruebas estadísticas, realizadas por clases comparadas de dos en dos ${ }^{39}$, muestran que las diferencias en los ingresos y en el mantenimiento de trabajo son sistemáticamente significativas cuando se comparan los resultados de las clases más alta y alta con las clases media y baja (aceptando una tasa de error del 5\% o menos), con la excepción de la variable sobre trabajadores dependientes, en la que solo la comparación de la clase más alta con todas las demás es significativa.

Cuanto más rico sea el hogar, más probabilidades hay de que más personas tengan un trabajo y que éste se efectúe en una relación de dependencia. La mayoría de hogares ricos tiene una relación de dependencia ( $76 \%$ del total) y, mientras menor sea la clase social, este porcentaje disminuye. En las clases altas la relación de dependencia se encuentra en $68 \%$, en las medias en $64 \%$ y en las bajas en 56\%. Cuanto más pobre es el hogar, más probable es que uno haya tenido que dejar de trabajar a causa del confinamiento. Se puede observar que el teletrabajo es posible, principalmente, para las personas de las clases más acomodadas: el $61 \%$ de los hogares pobres dejó de trabajar y solo $24 \%$ hace teletrabajo durante la cuarentena.

En cuanto a la evolución de los ingresos, más de la mitad de los hogares pobres perdió todos o la mayoría de sus ingresos durante la cuarentena, mientras que solo uno de cinco hogares mantiene sus ingresos sin variación o con una ligera disminución. Estos datos contrastan con la situación económica de las clases más altas y media, quienes menos han visto afectada su situación. Así, entre los más ricos, $43 \%$ mantiene sus ingresos y $39 \%$ ha visto una ligera disminución de los mismos.

\footnotetext{
${ }^{39}$ Se realizaron Test-T para las variables cuantitativas relativas a los trabajadores (las respuestas corresponden a un porcentaje de un número de trabajadores sobre el total de trabajadores del hogar); se realizaron tests de Chi2 para las variables cualitativas relativas a los hogares (los porcentajes expresados corresponden a una respuesta de sí o no a la pregunta formulada).
} 
Empobrecimiento de los hogares y cambios en el abastecimiento de alimentos por la COVID-19 en Lima...

La primera respuesta a la vulnerabilidad económica de los más pobres fue el establecimiento por parte del gobierno del Bono "Yo me quedo en casa", un subsidio monetario de S/. 380 para hogares en pobreza y pobreza extrema ${ }^{40}$. Sin embargo, muy pocas personas encuestadas señalan que recibieron dicho beneficio. A pesar de esta situación, vemos que únicamente uno de cinco hogares pobres se beneficia del Bono ofrecido por el Gobierno, cifra que es un poco menor a la de los hogares de clase media. Extrañamente, notamos que algunos hogares ricos (4 de 126) y altos (1 de 99) se benefician de esta medida.

Por otro lado, casi todos los hogares más pobres están utilizando sus ahorros para hacer frente a la caída de los ingresos, en comparación con poco más de un tercio de los hogares más ricos. Siete de diez hogares de clase media manifiestan que están utilizando dinero de sus ahorros durante la cuarentena, y es el caso también para uno de cada dos hogares de clase alta y uno de tres de la clase más alta.

Entre los hogares que utilizan sus ahorros para hacer frente a las dificultades económicas, volvemos a observar fuertes disparidades entre las clases sociales en términos del tiempo en que estos ahorros compensarán la pérdida de ingresos. Preguntamos a estos hogares hasta cuándo creían que les alcanzarían sus ahorros, y ocho de cada diez hogares pobres y de clase media dicen que no les quedará más dinero después de un mes. En detalle, se puede observar en la figura 3 que la mitad de los hogares de la clase baja habrá gastado la totalidad de sus ahorros en dos semanas, en comparación con ocho y once semanas para las dos clases más ricas. En otras palabras, mientras más pobre es un hogar, más rápido se les acabará el dinero.

Figura 3. Tiempo (meses) en que los hogares podrán hacer durar sus ahorros según clase social

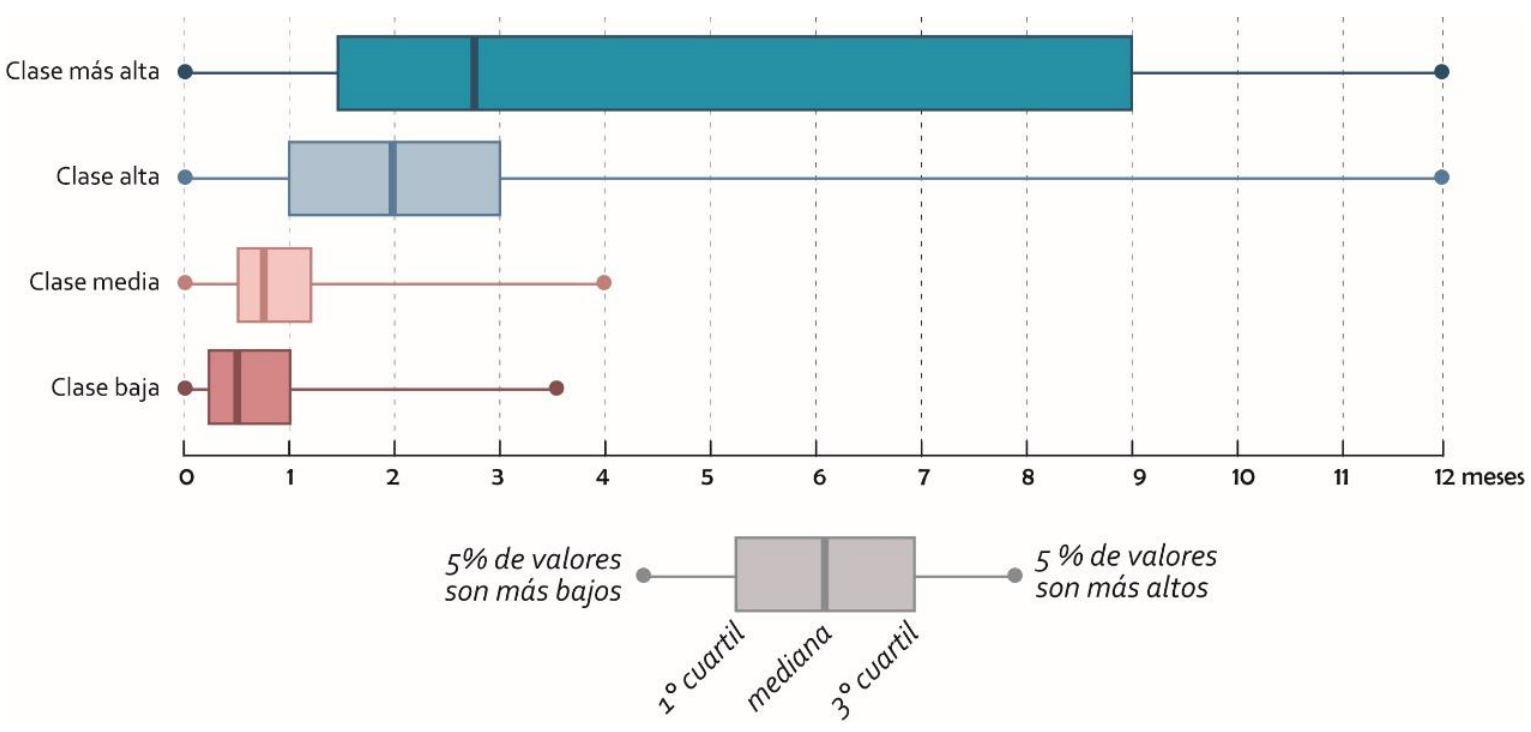

Fuente: Encuesta propia. Elaboración: autores, abril 2020.

\footnotetext{
${ }^{40}$ La selección de estos hogares se hizo por el Sistema de Focalización de Hogares y contemplaba solo a hogares con mayor riesgo sanitario en el ámbito urbano (Gobierno del Perú, 2020b <https://www.gob.pe/8782-acceder-al-bonoyo-me-quedo-en-casa>).
} 
La vulnerabilidad de los hogares más pobres no parece atenuarse con el paso del tiempo. En la encuesta se preguntó, a los hogares que ya hacían uso de sus ahorros, cómo pensaban resolver las necesidades económicas del hogar si se prolonga la cuarentena hasta el mes de mayo o más y, en general, las estrategias difieren según la clase social (ver Figura 4). Las estrategias basadas en el uso de los ahorros y el trabajo se desvanecen como opciones para los hogares más pobres, mientras que permanecen como real alternativa para las clases más adineradas.

\section{Figura 4. Estrategias económicas según clase social en caso de prolongación de la cuarentena al mes de mayo o más}

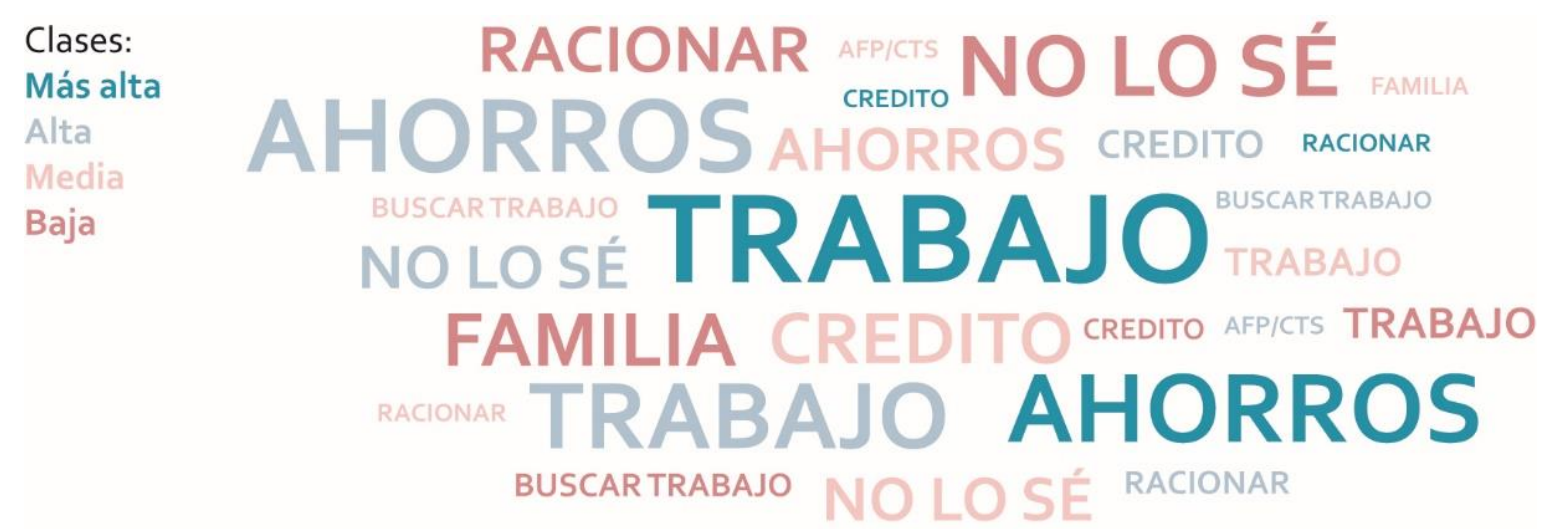

Fuente: Encuesta propia. Elaboración: autores, abril 2020.

En efecto, los hogares más ricos absorberían fácilmente las restricciones de la cuarentena gracias a los ingresos del trabajo vigente (cuatro de diez hogares) y los ahorros (tres de diez hogares). Los hogares de clase alta también recurren principalmente a estas alternativas y considerarían, más significativamente, la posibilidad de financiar sus gastos con préstamos de algún banco y con un mayor racionamiento de los recursos disponibles (uno de diez hogares, respectivamente). Asimismo, algunos hogares de clase alta y media manifiestan que retirarían dinero de los fondos de pensiones (AFP) u otros fondos (CTS). Los hogares de clase media apuntan mayormente al crédito, a los ahorros, o manifiestan no saber qué harían (uno de cinco hogares, respectivamente). La incertidumbre es, contradictoriamente, la principal alternativa de una cuarta parte de los hogares más pobres, quienes no saben cómo harán para sobrellevar económicamente esta situación. Las estrategias para este grupo oscilan entre pedir ayuda a familiares o amigos (uno de cinco hogares), racionar los recursos con los que se cuenta (también uno de cinco hogares), seguir trabajando o buscar algún trabajo (uno de cada diez hogares).

Las respuestas que señalan el racionamiento de recursos generalmente ponen ejemplos relacionados a la alimentación, como cambiar hábitos alimenticios, y al uso de dinero reservado para otros gastos. Por ejemplo, tuvimos algunas respuestas donde indicaban que sobrellevarían la cuarentena con dinero que estaba reservado para la educación de los hijos (compra de útiles escolares y uniformes). También tuvimos respuestas que señalaban que venderían objetos del hogar para hacer frente a las necesidades económicas. Finalmente, algunas respuestas apuntaban a refinanciar y aplazar deudas ya existentes con el banco, retirar dinero de cuentas de ahorro a plazo fijo o "regresar a provincia". 
Empobrecimiento de los hogares y cambios en el abastecimiento de alimentos por la COVID-19 en Lima...

Este último punto se reveló como una alternativa masiva en los días posteriores a la publicación de nuestros resultados: el desplazamiento de la población fuera de Lima Metropolitana ha sido forzado por las dificultades económicas que atraviesan los hogares ${ }^{41}$. La masiva movilización de hogares para irse de Lima y regresar a sus lugares de origen ha suscitado que el Estado destine recursos para que los Gobiernos Regionales faciliten el transporte de estas personas y habiliten, ya sea en Lima o en las capitales de región, lugares donde puedan hacer la cuarentena. Sin embargo, las iniciativas gubernamentales encuentran limitaciones presupuestales y de infraestructura.

Vemos entonces que las consecuencias directas e indirectas del confinamiento fueron subestimadas o estuvieron mal evaluadas desde el inicio y, sobre todo, conocían muy mal la vulnerabilidad de los hogares más pobres. Además, la vulnerabilidad de estos hogares se extiende también a la cobertura de salud porque, cuanto más pobre es uno, menos probable es que toda su familia cuente con algún seguro de salud. Del total de encuestados, el 36\% manifiesta que solo algunos miembros de la familia cuentan con seguro de salud, lo que muestra que hay situaciones desiguales incluso al interior de una familia. En los hogares más ricos, la mayoría manifiesta estar cubierta por un seguro privado, público, o por ambos (69\%). En $27 \%$ de estos hogares solo algunos miembros están cubiertos y el $4 \%$ restante señala que ningún miembro lo está. En la mayoría de los hogares más pobres solo algunos miembros del hogar están cubiertos (41\%) y un cuarto de los hogares manifiesta que ningún miembro tiene seguro.

Al respecto, es interesante observar que, aproximadamente la mitad de los hogares, independientemente de la clase, no sabe si estarán cubiertos en caso de que uno de los miembros necesite ser tratado a causa de COVID-19. Ese resultado pone de relieve algunos de los problemas de comunicación de parte del Ministerio de Salud y, también, revela la desconfianza existente hacia el sistema de salud en el país. Tal incertidumbre también se comprende por el hecho de que la pandemia del COVID-19 plantea una situación sin precedentes, donde las autoridades toman medidas precipitadas sobre la marcha y donde la emergencia desborda las capacidades existentes ${ }^{42}$.

\section{Persistencia de brechas de género en la compra de alimentos durante la cuarentena}

En el Perú, la metrópoli de Lima registra el mayor número de decesos a causa de COVID-19 (53\% del total nacional) y, según las pruebas de despistaje realizadas, también concentra el mayor número de personas infectadas $\left(76 \%\right.$ de casos). ${ }^{43}$ Por recomendación del Gobierno se estableció

\footnotetext{
${ }^{41}$ Ver el reportaje hecho por Ralph Zapata, Geraldine Santos, Magali Estrada, Alicia Tovar, Yanua Atamaín, Karin Chacón, Jorge Carrillo, Claudia Chávez, Gustavo Callapiña y Clarys Cárdenas: "La dura travesía de los más pobres: pandemia y desempleo expulsan a miles de migrantes", en: <https:/ojo-publico.com/1786/desplazados-por-lapandemia-la-travesia-de-los-mas-pobres?fbclid=IwAR3mEdpC4SKhNWrFA_yWRjexvDn7twe8RiTpEbZFllmreeL0ivpe4vnveo>.

${ }^{42}$ Al respecto, un reportaje de IDL Reporteros denuncia la falsa información dada por el Ministerio de Salud respecto al total de muertos en el país a causa del Covid-19, cifra subestimada que habría sido desmentida por el registro de cadáveres incinerados en dos centros funerarios de Lima. Ver: <https://www.idl-reporteros.pe/los-muertos-que-elgobierno-no-cuenta/>.

${ }^{43}$ Hasta las 12 horas del viernes 24 de abril, Lima Metropolitana (los cincuenta distritos de Lima y Callao) registra 15 836 casos confirmados de Covid-19 y 306 fallecidos a la fecha, de un total de 20914 casos y 572 fallecidos a nivel nacional (MINSA, 2020a <https://www.gob.pe/institucion/minsa/noticias/112163-minsa-casos-confirmados-por-
} 
que las personas debían cumplir el distanciamiento social: guardar por lo menos un metro de distancia con otras personas y evitar aglomeraciones en espacios públicos ${ }^{44}$. Algunos investigadores han alertado sobre la urgencia de tomar medidas específicas en las zonas más vulnerables de la ciudad, en los distritos San Juan de Lurigancho, Comas, Los Olivos, Rímac, El Agustino, La Victoria, Villa María del Triunfo y San Juan de Miraflores ${ }^{45}$. En estos distritos, donde habita la población más pobre ${ }^{46}$, parece muy difícil evitar la aglomeración y cumplir con el distanciamiento social, debido a que no existen suficientes equipamientos públicos o privados que permitan la circulación distanciada de las personas.

Los resultados de nuestra encuesta confirman que la medida de la cuarentena impactó en la movilidad de la población. Desde que inició la cuarentena (hasta la fecha de la encuesta), en todas las clases sociales se registró una disminución de la frecuencia de los viajes para comprar alimentos, especialmente entre los hogares más pobres (ver Figura 5).

Figura 5. Cambios en los hábitos de abastecimiento de alimentos después de la cuarentena
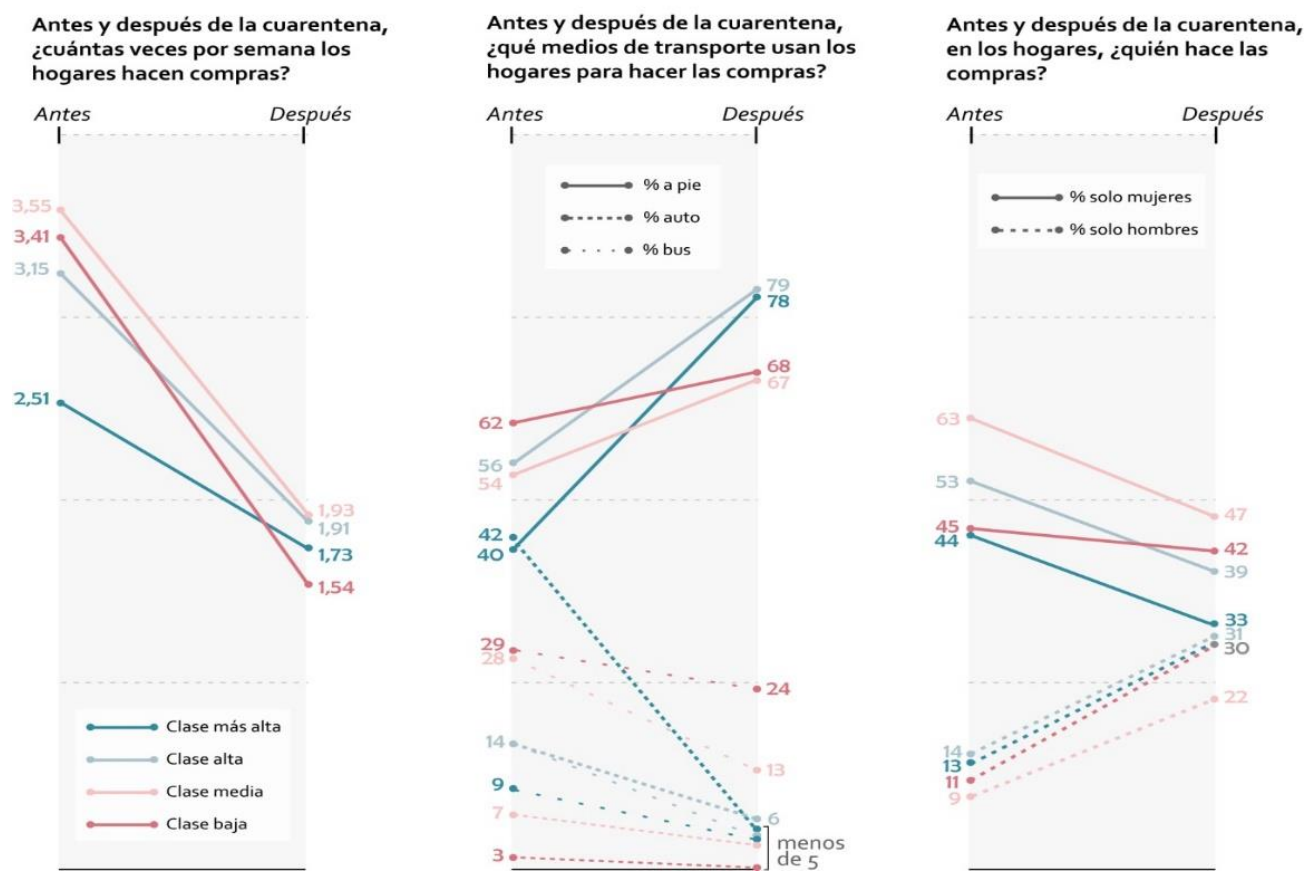

Fuente: Encuesta propia. Elaboración: autores, abril 2020.

coronavirus-COVID-19-ascienden-a-6-848-en-el-peru-comunicado-n-62>

$\mathrm{y}$

$2020 b$

<https://covid19.minsa.gob.pe/sala_situacional.asp>.). Preocupa el alto número de fallecidos en Lambayeque, $19 \%$ del total nacional.

${ }^{44}$ En la página del Gobierno del Perú se recomienda mantener un metro de distancia y evitar "(...) el contacto directo con personas que muestren síntomas como los del resfrío o gripe" (Gobierno del Perú, 2020 <https://www.gob.pe/8663-ministerio-de-salud-como-prevenir-el-coronavirus>).

45 Fort et al, 2020a <http://www.grade.org.pe/novedades/zonas-prioritarias-para-la-prevencion-y-control-delcontagio-del-COVID-19-en-lima-por-ricardo-fort-y-alvaro-espinoza/>

$\mathrm{y}$

$2020 b$

<https://www.grade.org.pe/novedades/potenciales-focos-de-contagio-del-COVID-19-mercados-y-supermercados/>.

46 INEI, 2016. 
Empobrecimiento de los hogares y cambios en el abastecimiento de alimentos por la COVID-I9 en Lima...

Se observan diferencias entre las clases sociales respecto a la disminución del número de veces por semana en que hacían compras. Antes de la cuarentena, los hogares más pobres y de clase media iban más de tres veces por semana a hacer compras, lo mismo que los hogares de clase alta. Pero este hábito cambió con la cuarentena, y en todas las clases sociales los hogares señalan que van a hacer compras menos de dos veces por semana. Más de la mitad de los hogares de clase más alta no disminuyó el número de veces por semana en que hacía compras y solo lo hizo un 44\%, que pasó de 2.51 a 1.73. En las otras clases, más de la mitad de hogares sí disminuyó el número de veces por semana en que hacía compras: es el caso de $58 \%$ de hogares de clase alta, $68 \%$ de hogares de clase media y $67 \%$ de hogares de clase baja. De hecho, los hogares más pobres son los que más disminuyeron el número de veces por semana: pasaron de 3.41 a 1.54 veces.

Por otro lado, es lógico observar un aumento de los desplazamientos a pie para hacer compras de alimentos, especialmente para los hogares más ricos, que parecen haber abandonado los viajes en auto desde el inicio del confinamiento: menos del 5\% utiliza hoy este modo de transporte, que antes era utilizado en un 42\%. Por otro lado, los hogares menos acomodados usan menos el transporte público. El mototaxi es usado principalmente por algunos hogares de la clase media, quienes antes y después del confinamiento mantienen el uso casi de manera invariable (alrededor de 5\%). Observamos que el uso del taxi se ha incrementado, principalmente en los hogares de clase media (pasó del 2\% al 7\%) y más alta (pasaron de 3\% a 6\%). En la clase alta se modificó ligeramente (pasó de $8 \%$ a $9 \%$ ).

Respecto a la distribución de tareas según género, los encuestados afirman que las mujeres compran los alimentos para el hogar con mayor regularidad que los hombres, y esto es aún más cierto en los hogares pobres. Empero, el reparto de tareas sería mucho más equilibrado desde la crisis ya que los hombres jefes de hogar parecen tener mayor participación en esta tarea que, durante la cuarentena, recae menos en mujeres jefas de hogar. Ha aumentado la participación de alguna mujer del hogar en esta tarea y aún más la de algún hombre del hogar, aunque para todas las clases se sigue observando desigualdad de género en la realización de estas actividades. ${ }^{47}$

Observamos que, durante la cuarentena, hay mayor participación de los hombres en las tareas de compra de alimentos y artículos de primera necesidad en aquellos hogares donde, antes de la cuarentena, dichas tareas recaían exclusivamente en mujeres. Sin embargo, pese a la reducción de esta brecha, aún persisten diferencias entre los géneros y las tareas siguen recayendo principalmente en las mujeres. No vemos diferencia de clase en este cambio de comportamiento pues, de manera general, uno de cinco hogares donde antes no participaban los hombres ahora registran su participación. En el caso de los hogares más pobres y más ricos es menor la disminución de la participación de las mujeres y, para ambas clases, solo el 19\% de hogares donde

\footnotetext{
${ }^{47}$ Antes del confinamiento, en los hogares más pobres las compras las realizaban las mujeres y hombres del hogar (42\%), la mujer jefa del hogar (27\%), alguna mujer del hogar (18\%), el hombre jefe del hogar (9\%) o algún hombre del hogar (3\%). En la clase media, las compras de alimentos las realizaban principalmente mujeres jefas de hogar (42\%), mujeres y hombres del hogar (28\%), alguna mujer (22\%), el hombre jefe de hogar (6\%) o algún hombre del hogar $(2 \%)$. En la clase alta, esta tarea o recaía en mujeres jefas de hogar (33\%) o se repartía entre mujeres y hombres del hogar (33\%), la realizaba alguna mujer del hogar (19\%), el hombre jefe de hogar (10\%) o algún hombre del hogar (4\%). Por último, en la clase más alta, las compras de alimentos las realizaban mujeres y hombres del hogar (43\%), mujeres jefas de hogar (34\%), hombres jefes de hogar (11\%), alguna mujer del hogar (10\%) o algún hombre del hogar $(2 \%)$.
} 
antes no participaban los hombres ahora sí lo hacen. En las clases media y alta hay mayor participación de los hombres durante la cuarentena: $22 \%$ y $24 \%$ respectivamente.

Las respuestas concernientes a los días en que en los hogares fueron a hacer las compras, después de la entrada en vigor del "pico y placa por género", muestran que las dinámicas de compra son, en general, similares a las anteriores a la cuarentena. Una diferencia importante es que, después de decretada la medida, hay visitas más frecuentes a todos los lugares de comercio de alimentos disponibles, los hogares más acomodados tienden a frecuentar los supermercados más a menudo que los mercados o bodegas y los hogares más pobres tienden a frecuentar más los mercados (ver Figura 6 y 7).

Figura 6. Lugares frecuentados durante el "pico y placa por género" según clases sociales

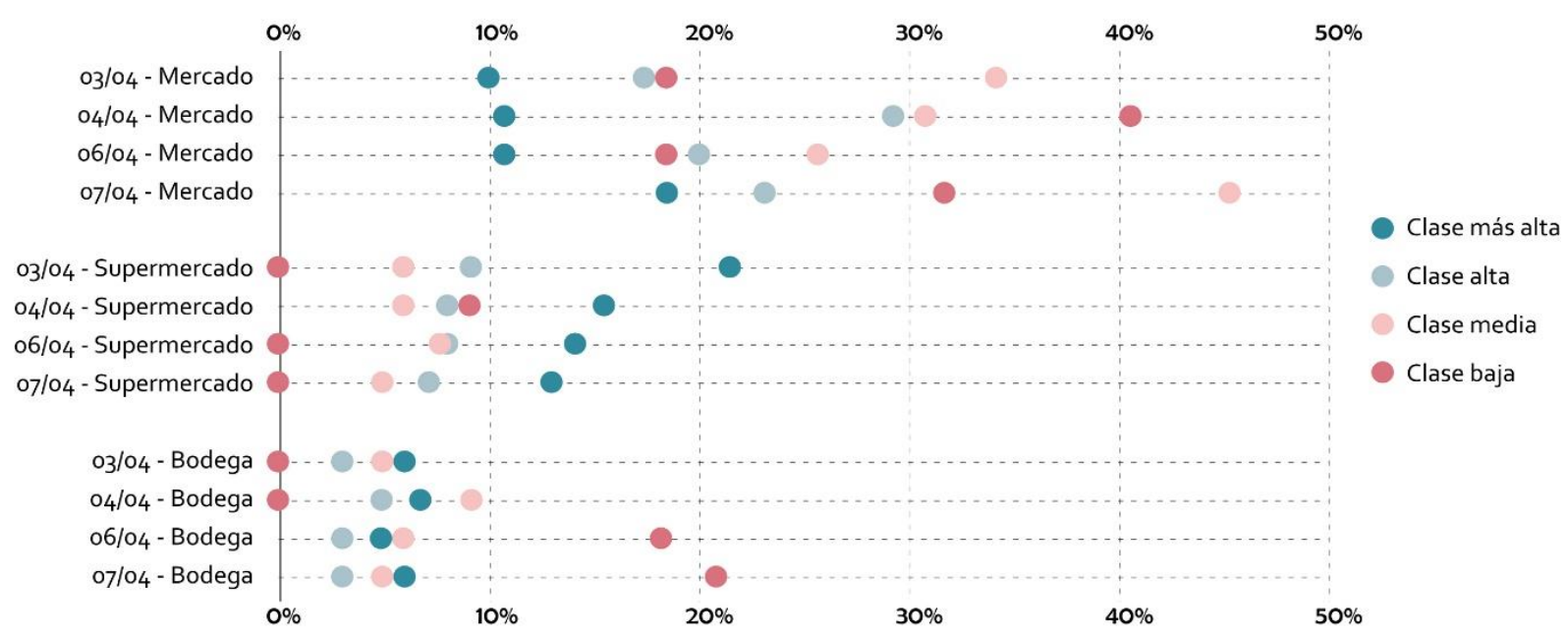

Fuente: Encuesta propia. Elaboración: autores, abril 2020.

Figura 7. Promedio de lugares frecuentados durante el "pico y placa por género" según hombres, mujeres y clases sociales

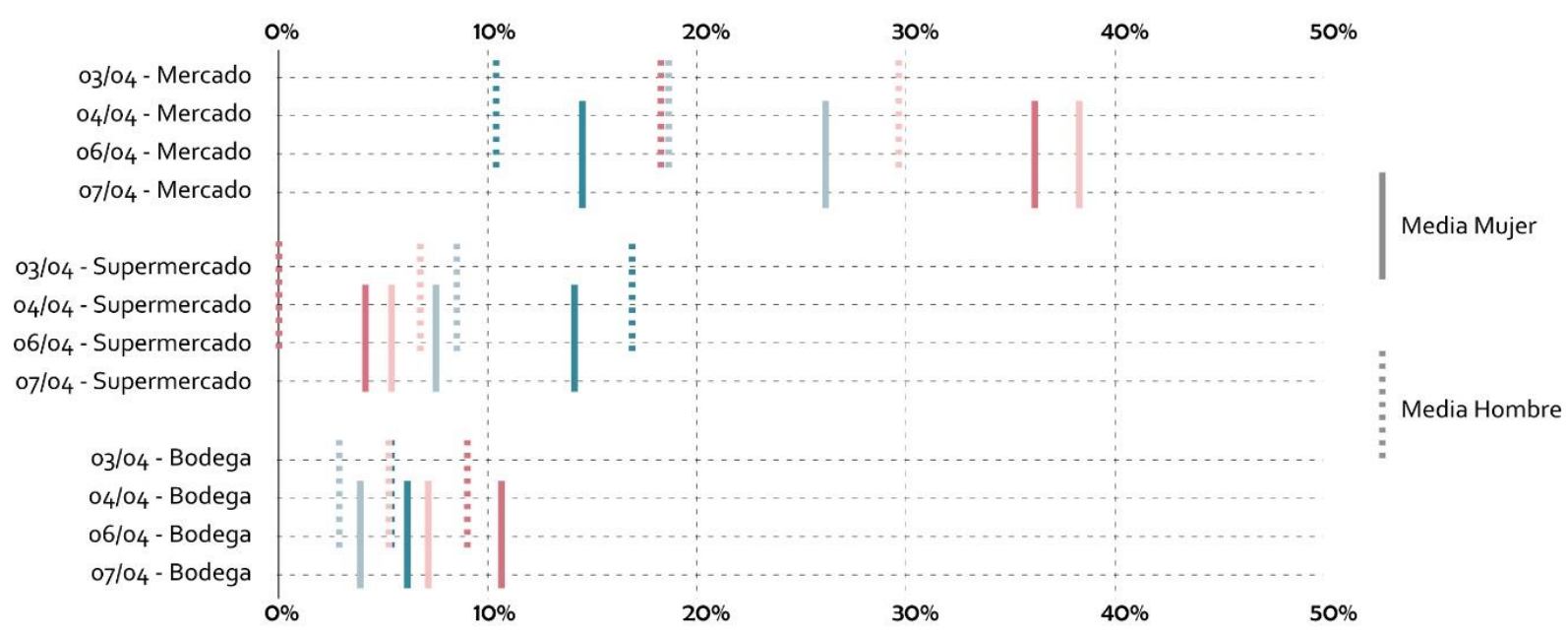

Fuente: Encuesta propia. Elaboración: autores, abril 2020. 
Empobrecimiento de los hogares y cambios en el abastecimiento de alimentos por la COVID-I9 en Lima...

Las respuestas de los encuestados muestran que las compras de alimentos se hacen principalmente en tres tipos de lugares: mercados, supermercados y bodegas, lugares que son frecuentados por hogares de todas las clases sociales. Antes de la cuarentena, los hogares más pobres iban mayormente al mercado (91\%), al supermercado (33\%) o a bodegas (30\%); los hogares de clase media siguen ese patrón $(85 \%, 26 \%$ y $20 \%$ respectivamente), al igual que los hogares de clase alta (78\%, 59\% y $26 \%$ respectivamente). Los hogares más ricos iban más al supermercado (75\%), al mercado (58\%) o a las bodegas (19\%), lo que guarda sentido con el uso predominante de automóviles en sus desplazamientos para realizar las compras. Otros establecimientos frecuentados por los hogares corresponden a bioferias y son más populares entre las clases más altas. Durante la cuarentena, vemos que los hogares más acomodados tienden a frecuentar más a menudo los supermercados y observamos también un aumento -todavía tímido, pero en progreso- de los repartos a domicilio.

Observamos también que, durante la vigencia del "pico y placa por género", aumentó el número de veces por semana en que se hacían las compras. Extrapolando, podríamos considerar que las compras semanales aumentaron a 2.5 y 3 veces. Según las respuestas de los encuestados, en los días precedentes a esta medida se hacían las compras menos de dos veces por semana. Sin embargo, razonablemente podemos pensar que esto se explica porque, en muchos hogares, se realizan compras los fines de semana, a lo que se sumó el anuncio presidencial que prohibió salir los días 09 y 10 de abril, lo que puede haber causado un aumento del número de compradoras el martes 07 , día en que únicamente podían salir las mujeres.

El viernes 03 de abril, más de la mitad de encuestados en todas las clases sociales manifiesta que no hicieron compras ese día. Esta cifra es mayor entre los hogares más pobres, donde ocho de cada diez personas compraron en el mercado o en varios establecimientos. Los hombres de los hogares de clase media fueron los que más salieron ese día, principalmente a mercados (uno de cada tres hogares), supermercados, bodegas, o a varios establecimientos. En la clase más alta no salieron en más de la mitad de hogares, y los que salieron fueron principalmente al supermercado, al mercado o a bodegas. El lunes 06 de abril, día en que le tocó salir nuevamente a los hombres, nadie salió en el $60 \%$ de hogares de todas las clases sociales.

El sábado 04 de abril, día en que salieron las mujeres, en más de la mitad de hogares sí salieron ese día, menos en las clases más altas. En los hogares más pobres, las mujeres fueron principalmente al mercado (41\%), al supermercado (9\%) o a varios lugares (6\%). Más de la mitad de los hogares más ricos no salió ese día, y las mujeres que salieron fueron principalmente al supermercado (16\%), al mercado (11\%), a la bodega (7\%), o recurrieron a otros modos de aprovisionamiento que incluyen la compra con reparto a domicilio. Por último, el martes 07 de abril, más de un tercio de hogares -de todas las clases sociales- sí hizo compras y el mercado fue el lugar más frecuentado por las mujeres de todas las clases sociales. De manera general, se observa que las mujeres van al mercado con más frecuencia que los hombres.

La promulgación del "pico y placa por género" buscaba limitar aún más la aglomeración de personas en los espacios públicos, específicamente en lugares de abastecimiento de alimentos. Sin embargo, los creadores de esta medida no tomaron en cuenta la desigual distribución de las tareas de abastecimiento de alimentos en los hogares y, a los pocos días de su entrada en vigor, el Gobierno reconoció la ineficiencia de la medida y dictaminó su anulación. Nuestros resultados 
sobre distribución por género de estas tareas muestran que las mismas recayeron más pesadamente en las mujeres los días en que rigió esta medida gubernamental. Aunque efímera, la norma desafió la organización familiar para resolver las tareas domésticas y expuso más a las mujeres al contagio del virus.

\section{Conclusiones}

Si la vulnerabilidad a los virus no conoce fronteras, la vulnerabilidad de la población a las consecuencias socioeconómicas de la medida de confinamiento parece ser mayor en las grandes ciudades de los países del sur, particularmente para sus poblaciones más pobres.

En Lima, la cuarentena impuesta por el gobierno peruano muestra, hasta qué punto, los hogares más pobres de la ciudad fueron muy vulnerables a esta medida que trajo, como consecuencia de la prohibición de salir a trabajar, el rápido consumo de sus ahorros y su empobrecimiento. Estos hechos confirmaron nuestra primera hipótesis: entre los más pobres, quienes tienen un trabajo son generalmente trabajadores independientes que no pueden realizar sus labores a distancia, lo que ha provocado una disminución muy significativa de sus ingresos. Así, más de la mitad de los hogares más pobres no tiene ningún ingreso o tiene pocos ingresos hoy en día, y debieron utilizar rápidamente los escasos ahorros que habían reservado. La situación de estos hogares se reveló rápidamente catastrófica y se observaron desplazamientos de miles de personas desde Lima hacia sus lugares de origen; desde ahí, se esperaba resistir a la crisis con ayuda de sus redes familiares de solidaridad. El gobierno intentó contener las penurias económicas con la promulgación del bono "Yo me quedo en casa", pero los problemas en su distribución dejaron desamparados a quienes más necesitaban apoyo.

Los problemas económicos que provocó la cuarentena alcanzaron también a las clases medias, que elegirían sacrificar garantías del futuro para poder sobrellevar el presente. Al contrario, una gran parte de las clases más acomodadas seguía trabajando, ya sea en el lugar de trabajo habitual o a distancia, y estos hogares tenían ahorros para pasar los próximos meses con serenidad.

Todas las observaciones apoyan la tesis según la cual, durante las crisis, son las poblaciones más pobres las que más sufren. Esto cuestiona los límites de las medidas asociadas a la cuarentena, estricta y generalizada, tanto en el Perú como en otros países con mucha población pobre. Las observaciones muestran que los más pobres deberían ser ampliamente protegidos antes de aplicar políticas de esta naturaleza, y que las mismas deben ser acompañadas de otras medidas de protección social para que las personas puedan, efectivamente, quedarse en casa. El ejemplo de la cuarentena en Lima muestra que, tarde o temprano, legal o ilegalmente, ciertas poblaciones vulnerables saldrán a buscar recursos indispensables para su supervivencia.

En relación a nuestra segunda hipótesis, la medida "pico y placa por género" no contribuyó a reducir la frecuencia de los desplazamientos con fines alimentarios y fue rápidamente abandonada por las autoridades peruanas. Incluso, la medida se reveló contraproducente a los fines del distanciamiento social pues, los días en que podían salir las mujeres, intensificó su concentración en los centros de abastecimiento. 
Empobrecimiento de los hogares y cambios en el abastecimiento de alimentos por la COVID-19 en Lima...

A partir de lo observado constatamos que, ya para la fecha en que el "pico y placa por género" empezó a funcionar, los hogares habían cambiado su comportamiento y reducido la frecuentación a los lugares de abastecimiento de alimentos, y parecía difícil para los hogares disminuir aún más este ritmo. Por otro lado, pese a una tendencia a la homogeneización, se observa también la continuidad de disparidades de género en las tareas de aprovisionamiento de alimentos, independientemente de la clase, lo que podría llevar a la mayor densidad de mujeres en ciertos lugares cuando las reglas de distanciamiento buscan apoyar lo contrario.

Finalmente, el trabajo resalta que, a veces, las medidas que buscan controlar excesivamente la vida social pueden resultar nefastas para la buena organización de la misma. En la crisis del COVID19, si bien las medidas de distanciamiento social pueden ser útiles para demorar la propagación del virus, también tienen límites que se revelaron claramente y mostraron que, incluso las consecuencias más evidentes del confinamiento no fueron estimadas a cabalidad.

\section{Bibliografía}

ADAM, David. Special report: The simulations driving the world's response to COVID-19. Nature [En línea], 2020, n 580, p. 316-318 <https://www.nature.com/articles/d41586-020-01003-6>. [25 de abril de 2020]. ISSN 1476-4687.

ALENCAR, Tadeu; RODRIGUES, Adriano; PINHEIRO, Diego; RODRIGUES, Tathiana; LACERDA, Juheina y Amanda FERNANDES. Pandemia COVID-19: o caráter emergencial das transferências de renda direta e indireta para a população vulnerável do estado de Goiás. Espaço $e$ Economia [En Línea], 2020, $\mathrm{n}^{\circ} 18<$ http://journals.openedition.org/espacoeconomia/13734>. [24 de abril de 2020].

BARREDA, José y Daniel RAMÍREZ CORZO. Lima: consolidación y expansión de una ciudad popular. In Perú Hoy: Las ciudades en el Perú. Lima: DESCO, 2004, p. 199-218.

BUJ BUJ, Antonio. La COVID-19 y las viejas epidemias. No es la Tercera Guerra Mundial, es el capitalismo.Ar@cne: revista electrónica de recursos en internet sobre geografía y ciencias sociales, [En línea], 2020, Núm. 1 <https://www.raco.cat/index.php/Aracne/article/view/367759> <https://revistes.ub.edu/index.php/aracne/article/view/31379/31378> [7 de mayo de 2020].

COMISIÓN ECONÓMICA PARA AMÉRICA LATINA Y EL CARIBE-CEPAL. Pandemia del COVID-19 llevará a la mayor contracción de la actividad económica en la historia de la región: caerá $-5,3 \%$ en 2020. [En línea]. 21 de abril de 2020 $<$ https://www.cepal.org/es/comunicados/pandemia-COVID-19-llevara-la-mayor-contraccion-laactividad-economica-la-historia-la> [24 de abril de 2020].

DAVIS, Mike. The Monster at Our Door: The Global Threat of Avian Flu. The New Press, 2005, $224 \mathrm{p}$. 
DAVIS, Mike. The Monster enters. New Left Review [En línea]. 05 de abril de 2020 <https://newleftreview.org/issues/II122/articles/mike-davis-in-a-plague-year> [24 de abril de 2020].

DE JANVRY, Alain y Elisabeth SADOULET. Growth, poverty, and inequality in Latin America: a causal analysis, 1970-94. Review of Income and Wealth, 2005, vol. 46, Issue 3 <https://doi.org/10.1111/j.1475-4991.2000.tb00843.x>. [25 de abril de 2020].

DELER, Jean-Paul. Lima 1940-1970: Aspects de la croissance d'une capitale sud-américaine. Travaux et documents de géographie tropicale, $N^{\circ} 15$, Centre d'études de Géographie TropicaleInstitut Français d'études Andines, Talence (France), 1974.

DRIANT, Jean-Claude. Las barriadas de Lima. Historia e interpretación. Lima: IFEA-DESCO, 1991.

DRIANT, Jean Claude y Gustavo RIOFRIO. ¿Qué vivienda han construido? Lima: Institut français d'études andines, 1987.

ESPAÇO E ECONOMIA: REVISTA BRASILEIRA DE GEOGRAFIA ECONÔMICA. Edição Especial: Dossiê Coronavírus - Parte I [En línea], 2020a, año IX, $\mathrm{n}^{\circ} 17$ <https://doi.org/10.4000/espacoeconomia.10071>. [24 de abril de 2020].

ESPAÇO E ECONOMIA: REVISTA BRASILEIRA DE GEOGRAFIA ECONÔMICA. Edição Especial: Dossiê Coronavírus - Parte II [En línea], 2020b, año IX, número 18 <https://doi.org/10.4000/espacoeconomia.11397>. [24 de abril de 2020].

FERGUSON, Neil M.; LAYDON, Daniel; NEDJATI-GILANI, Gemma; IMAI, Natsuko; AINSLIE, Kylie; BAGUELIN, Marc; BHATIA, Sangeeta; BOONYASIRI, Adhiratha; CUCUNUBÁ, Zulma; CUOMO-DANNENBURG, Gina; DIGHE, Amy; DORIGATTI, Ilaria; FU, Han; GAYTHORPE, Katy; GREEN, Will; HAMLET, Arran; HINSLEY, Wes; OKELL, Lucy C.; VAN ELSLAND, Sabine; THOMPSON, Hayley; VERITY, Robert; VOLZ, Erik; WANG, Haowei; WANG, Yuanrong; WALKER, Patrick G.T.; WALTERS, Caroline; WINSKILL, Peter; WHITTAKER, Charles; A DONNELLY, Christl; RILEY, Steven y Azra C. GHANI. Reporte 9: Impacto de las intervenciones no farmacéuticas (INF) para reducir la mortalidad y demanda en los sistemas de salud frente a COVID-19. Imperial College London [En línea], 29 de marzo de $2020<$ https://spiral.imperial.ac.uk:8443/bitstream/10044/1/77482/15/2020-03-16-COVID19Report-9-Spanish.pdf> [24 de abril de 2020].

FORT, Ricardo; ESPINOZA, Álvaro; RIVAROLA, Rodrigo y Mario MALQUICHAGUA. Zonas prioritarias para la prevención y control del contagio del COVID-19 en Lima. GRADE [En línea], 2020a <http://www.grade.org.pe/novedades/zonas-prioritarias-para-la-prevencion-y-control-delcontagio-del-COVID-19-en-lima-por-ricardo-fort-y-alvaro-espinoza/>. [11 de abril de 2020].

FORT, Ricardo; ESPINOZA, Álvaro; RIVAROLA, Rodrigo y Mario MALQUICHAGUA. Potenciales focos de contagio del COVID-19: mercados y supermercados. GRADE [En línea], 
Empobrecimiento de los hogares y cambios en el abastecimiento de alimentos por la COVID-19 en Lima...

$2020 \mathrm{~b}<\mathrm{https}$ //www.grade.org.pe/novedades/potenciales-focos-de-contagio-del-COVID-19mercados-y-supermercados/>. [11 de abril de 2020].

FORTES, Alexandre; DIAS DE OLIVEIRA, Leandro y Gustavo MOTA DE SOUSA. A COVID19 na Baixada Fluminense: Colapso e apreensão a partir da periferia metropolitana do Rio de Janeiro. Espaço $e$ Economia. [En línea], 2020, $\mathrm{n}^{\circ} 18$ <http://journals.openedition.org/espacoeconomia/13591>. [24 de abril de 2020].

GAO, Jianjun; TIAN, Zhenxue y Xu YANG. Breakthrough: Chloroquine phosphate has shown apparent efficacy in treatment of COVID-19 associated pneumonia in clinical studies. BioScience Trands, 2020, vol. 14, issue 1, p.72-73.

GILBERT, Marius; PULLANO, Giulia; PINOTTI, Francesco; VALDANO, Eugenio; POLETTO, Chiara; BOELLE, Pierre-Yves; D'ORTENZIO, Eric; YAZDANPANAH, Yazdan; EHOLIE, Serge Paul; ALTMANN, Mathias; GUTIERREZ, Bernardo; KRAEMER, Moritz y Vittoria COLIZZA. Preparedness and vulnerability of African countries against introductions of 2019-nCoV. MedRxiv. The preprint server for health sciences [En línea], 07 de febrero de 2020 <https://www.medrxiv.org/content/10.1101/2020.02.05.20020792v1>. [10 de mayo de 2020].

GOBIERNO DEL PERÚ. ¿Cómo prevenir el coronavirus? GOB.PE. [En línea], 2020 <https://www.gob.pe/8663-ministerio-de-salud-como-prevenir-el-coronavirus>. [11 de abril de 2020].

GOBIERNO DEL PERÚ. Consultar si te corresponde el bono por el Decreto de Urgencia para frenar la propagación del COVID-19. GOB.PE [En línea], 2020b <https://www.gob.pe/8782acceder-al-bono-yo-me-quedo-en-casa>. [24 de abril de 2020].

HALEY, Ella; CAXAJ, Susana; GEORGE, Glynis; HENNEBRY, Jenna; MARTELL, Eliseo y Janet MCLAUGHLIN. Migrant farmworkers face heightened vulnerabilities during COVID-19. Journal of Agriculture, Food Systems, and Community Development, 2020, vol. 9, n³, p. 1-5 <https://www.foodsystemsjournal.org/index.php/fsj/article/view/810>. [10 de mayo de 2020].

HARVEY, David. Anti-Capitalist Politics in the Time of COVID-19. Jacobin Magazine [En línea], 20 de marzo de 2020 <https://jacobinmag.com/2020/03/david-harvey-coronavirus-politicaleconomy-disruptions>. [24 de abril de 2020].

INSTITUTO NACIONAL DE ESTADÍSTICA E INFORMÁTICA INEI. Planos estratificados de Lima Metropolitana a Nivel de Manzana, 2016. Según ingresso per cápita del hogar, según grupos de pobreza monetária. Lima: INEI-IRD, 2016.

INSTITUTO NACIONAL DE ESTADÍSTICA E INFORMÁTICA INEI. Censos Nacionales 2017: XII de Población, VII de vivienda y III de Comunidades Indígenas [En línea], 2017 $<$ https://censos2017.inei.gob.pe/redatam/>. [24 de abril de 2020].

INSTITUTO NACIONAL DE ESTADÍSTICA E INFORMÁTICA INEI. Perú: Perfil Sociodemográfico. Informe Nacional. Lima: INEI, 2018. 
LI, Qun; GUAN, Xuhua; WU, Peng; WANG, Xiaoye y otros. Early Transmission Dynamics in Wuhan, China, of Novel Coronavirus-Infected Pneumonia. New England Journal of Medecine [En línea], 26 de marzo de 2020, n³82, p.1199-1207 <https://www.nejm.org/doi/full/10.1056/NEJMoa2001316> [24 de abril de 2020].

LIU, Ying; GAYLE, Albert A.; WILDER-SMITH, Annelies y Joacim ROCKLÖV. The reproductive number of COVID-19 is higher compared to SARS coronavirus. Journal of Travel Medicine [En línea], 2020, vol. 27, issue 2 <https://academic.oup.com/jtm/article/27/2/taaa021/5735319>. [24 de abril de 2020].

MÉNDEZ, Ricardo; PRADA-TRIGO, José. Crisis, desempleo y vulnerabilidad en Madrid. Scripta Nova. Revista Electrónica de Geografía y Ciencias Sociales. [En línea]. Barcelona: Universidad de Barcelona, 20 de abril de 2014, vol. XVIII, nº 474 <http://www.ub.edu/geocrit/sn/sn-474.htm〉. ISSN: 1138-9788.

MINISTERIO DE SALUD DEL PERÚ. Minsa: Casos confirmados por coronavirus COVID-19 ascienden a 6848 en el Perú (Comunicado $N^{\circ}$ 62) [En línea], 11 de abril de 2020a $<$ https://www.gob.pe/institucion/minsa/noticias/112163-minsa-casos-confirmados-porcoronavirus-COVID-19-ascienden-a-6-848-en-el-peru-comunicado-n-62>. [11 de abril de 2020].

MINISTERIO DE SALUD DEL PERÚ. (2020b). Sala Situacional COVID-19 [En línea], 24 de abril de 2020 <https://covid19.minsa.gob.pe/sala_situacional.asp>. [24 de abril de 2020].

PRADA-TRIGO, José. Espacios vulnerables, crisis y "post-crisis económica": trayectoria y persistencia a escala intraurbana. Scripta Nova. Revista Electrónica de Geografía y Ciencias Sociales [En Línea]. Barcelona: Universidad de Barcelona, 15 de marzo de 2018, vol. XXII, nº 586 <https://www.raco.cat/index.php/ScriptaNova/article/view/337246>. ISSN: 1138-9788.

RADIO PROGRAMAS DEL PERÚ -RPP. ¿Cuánto subieron los departamentos en cada zona de Lima entre 2007 y 2015? [En Línea]. Lima: RPP, 2015 <https://rpp.pe/economia/economia/cuantosubieron-los-precios-de-los-departlamentos-para-vivienda-en-cada-zona-de-lima-entre-2007-y2015-noticia-918034?ref=rpp> [11 de abril de 2020].

RAMÍREZ CORZO, Daniel y Gustavo RIOFRÍO. Formalización de la propiedad y mejoramiento de barrios: bien legal, bien marginal. Lima: DESCO, 2006.

RAN, Jing; MACGILLIVRAY, Brian; GONG, Yi y Tristram HALES. The application of frameworks for measuring social vulnerability and resilience to geophysical hazards within developing countries: A systematic review and narrative synthesis. Science of the Total Environment, 2020, vol.711, $\mathrm{n}^{\circ} 134486$.

ROMERO, Dalia y Célia LANDMANN. Crisis económica y mortalidad infantil en Latinoamérica desde los años ochenta. Cadernos de Saúde Pública [En línea], Rio de Janeiro, 2020, vol.16, n³, p.799-814 311X2000000300028>. $<$ https://www.scielo.br/scielo.php?script=sci_arttext\&pid=S0102- 
Empobrecimiento de los hogares y cambios en el abastecimiento de alimentos por la COVID-19 en Lima...

SOARES DE FARIAS, Heitor. O avanço da COVID-19 e o isolamento social como estratégia para redução da vulnerabilidade. Espaço e Economia. [En línea]. 08 de abril de 2020, n $^{\circ} 17$ <http://journals.openedition.org/espacoeconomia/11357>. [24 de abril de 2020].

TIMMERMAN, Peter. Vulnerability resilience and collapse of society. Toronto: Institute for Environmental Studies, 1981.

ZHOU, Fei; YU, Ting; DU, Ronghui; FAN, Guohui; LIU, Ying; LIU, Zhibo; XIANG, Jie; WANG, Yeming; SONG, Bin; GU, Xiaoying; GUAN, Lulu; WEI, Yuan; LI, Hui; WU, Xudong; XU, Jiuyang; TU, Shengjin; ZHANG, Yi; CHEN, Hua y Bin CAO. Clinical course and risk factors for mortality of adult inpatients with COVID-19 in Wuhan, China: a retrospective cohort study. The Lancet [En línea], 28 March-3 April 2020, vol. 395, issue 10229, p.1054-1062. <https://www.thelancet.com/pb-assets/Lancet/pdfs/S014067362305663.pdf> [24 de abril de 2020].

(C) Copyright: Tania Herrera Romero, Aurélien Reys, 2020.

(C) Copyright: Ar@cne, 2020.

Ficha bibliográfica:

HERRERA ROMERO, Tania; REYS, Aurélien. Empobrecimiento de los hogares y cambios en el abastecimiento de alimentos por la COVID-19 en Lima, Perú.Ar@cne. Revista Electrónica de Recursos de Internet sobre Geografía y Ciencias Sociales. Barcelona: Universidad de Barcelona, 1 de junio de 2020, vol. XXIV, $\mathrm{n}^{\mathrm{o}} 243$ <https://doi.org/10.1344/ara2020.243.31627>.

\section{Menú principal de Geo Crítica}

